\title{
Virus-induced gene-silencing in wheat spikes and grains and its application in functional analysis of HMW-GS-encoding genes
}

\author{
Meng Ma ${ }^{1,2}$, Yan Yan ${ }^{1,2}$, Li Huang ${ }^{3}$, Mingshun Chen ${ }^{4}$ and Huixian Zhao ${ }^{1,2^{*}}$
}

\begin{abstract}
Background: The Barley stripe mosaic virus (BSMV)-based vector has been developed and used for gene silencing in barley and wheat seedlings to assess gene functions in pathogen- or insect-resistance, but conditions for gene silencing in spikes and grains have not been evaluated. In this study, we explored the feasibility of using BSMV for gene silencing in wheat spikes or grains.

Results: Apparent photobleaching on the spikes infected with BSMV:PDS at heading stage was observed after13 days post inoculation (dpi), and persisted until 30dpi, while the spikes inoculated with BSMV:00 remained green during the same period. Grains of BSMV:PDS infected spikes also exhibited photobleaching. Molecular analysis indicated that photobleached spikes or grains resulted from the reduction of endogenous PDS transcript abundances, suggesting that BSMV:PDS was able to induce PDS silencing in wheat spikes and grains. Inoculation onto wheat spikes from heading to flowering stage was optimal for efficient silencing of PDS in wheat spikes. Furthermore, we used the BSMV-based system to reduce the transcript level of $1 B \times 14$, a gene encoding for High-molecular-weight glutenin subunit 1Bx14 (HMW-GS 1Bx14), by $97 \%$ in the grains of the BSMV:1Bx14 infected spikes at 15dpi, compared with that in BSMV:00 infected spikes, and the reduction persisted until at least 25 dpi. The amount of the HMW-GS 1 Bx 14 was also detectably decreased. The percentage of glutenin macropolymeric proteins in total proteins was significantly reduced in the grains of 1Bx14-silenced plants as compared with that in the grains of BSMV:00 infected control plants, indicating that HMV-GS 1Bx14 is one of major components participating in the formation of glutenin macropolymers in wheat grains.

Conclusion: This is one of the first reports of successful application of BSMV-based virus-induced-gene-silencing (VIGS) for gene knockdown in wheat spikes and grains and its application in functional analysis of the 1Bx14 gene. The established BSMV-VIGS system will be very useful in future research on functional analysis of genes contributing to grain quality and the metabolic networks in developing seeds of wheat.
\end{abstract}

Keywords: Triticum aestivum, Spike, Grain, Barley stripe mosaic virus (BSMV), Virus-induced gene silencing (VIGS), Functional genomics

\section{Background}

Wheat (Triticum aestivum L.) is one of the major staple crops for the human diet. With the increase in the global population, the shortage of foods has become more and more serious. Therefore, wheat yield and quality improvement has always been the most important target in

\footnotetext{
* Correspondence: hxzhao212@nwsuaf.edu.cn

${ }^{1}$ State Key Laboratory of Crop Stress Biology for Arid Areas, Yangling, Shaanxi 712100, China

${ }^{2}$ College of Life Sciences, Northwest A \& F University, Yangling, Shaanxi 712100, China

Full list of author information is available at the end of the article
}

wheat breeding programs. Although conventional breeding approaches via manipulating genetic variation have been very successful in improving the agronomically important traits of cereals, the next wave of crop improvement will require much greater knowledge of gene function [1].

The rapid advance in genomics [2,3] has greatly facilitated gene isolation and manipulation, generating huge quantities of transcript and putative gene sequences (http://www.ncbi.nlm.nih.gov/guide/dna-rna/). In addition, genomes of major crops including rice, maize, and wheat have been or are being sequenced. As

\section{Biomed Central}


a result of rapid advance in structural genomics, the availability of powerful tools for gene function analysis has become a bottleneck, especially for important crops beyond the few model plant species.

In model plants such as Arabidopsis and rice, two methods, i.e. T-DNA knockout libraries [4] and T-DNA activation libraries [5], have significantly accelerated the speed of gene functional identification. Large collections of plants that contain T-DNA insertions have been generated. Once plants have been identified with the desired phenotypes, isolation of relevant genes is readily accomplished by finding the genomic location of the T-DNA associated with the mutant phenotype [1]. However, none of these techniques can be used in wheat due to the large genome size and very low transformation efficiency which pose a technical challenge to produce the number of transformants needed to saturate the wheat genome. An additional complication for determining gene function through the analysis of loss-of-function mutations in wheat is the fact that all cultivated varieties are polyploid; therefore in most cases, expression of homeologous genes could mask loss-of-function phenotypes resulting from the disruption of the other homeologous alleles [1].

In recent years, virus-induced gene silencing (VIGS) has been developed as an effective genetics tool for assessing gene functions in a range of dicot plant species including Nicotiana spp. (tobacco), Pisum sativum (pea), Arabidopsis, Solanum lycopersicum (tomato) [6-9], and some monocot species Hordeum vulgare (barley), Triticum aestivum (wheat), and Zea mays (maize) [10-12]. VIGS was a mechanism of defense response naturally present in plants and other organisms through RNAmediated post-transcriptional gene silencing (PTGS) to fight pathogens $[13,14]$. In VIGS, viruses trigger defense machinery of the hosts related to post-transcriptional gene silencing, where double stranded RNA is converted into short interfering RNAs (siRNAs). A gene of interest can be introduced into a virus vector and the recombinant virus will trigger the host defense response and both the virus genome and the endogenous mRNAs homologous to the inserted target sequence become the targets for degradation $[15,16]$. Silencing initiated by VIGS will spread systemically along with the siRNA $[17,18]$, and by this method, it is possible to knockdown almost any gene of interest if a suitable vector is present for the plant species under investigation.

Many viral vectors for VIGS have been developed for various plant species [6,7,10,19-22]. However, so far, most VIGS protocols are established for gene silencing in vegetative tissues, with very limited success in reproductive and other tissues [23-29]. Gene silencing techniques for developing seeds will be very useful for studying gene functions in seed development and for seed quality improvement. For monocotyledons, two vectors, the Barley stripe mosaic virus (BSMV)-based vector for barley and wheat $[10,11]$ and the Brome mosaic virus (BMV)-based vector for barley, rice and maize [12], have been developed and are being widely used for gene silencing in seedlings [30-32]. More recently, Pacak et al. [33] presented the first evidence of BSMV induced gene silencing (BSMV-VIGS) in the roots of a monocotyledonous plant species. To date, however, no reports have been published on BSMV-VIGS in spikes or grains of monocotyledonous species. Genes expressed in spikes or grains are likely involved in important agronomic traits such as yield, quality and disease resistance, and therefore, revealing the functions of these genes will greatly facilitate the improvement of yield, quality and pathogen resistance in cereals [34-37]. Accordingly techniques for analyzing gene functions in spikes or grains are needed for functional analysis.

High-molecular-weight glutenin subunits (HMW-GSs) are a group of endosperm storage proteins in wheat encoded by a multi-gene family. Members in this gene family possess highly homologous sequences, as found in Glu-A1, Glu-B1 and Glu-D1 loci on the long arm of chromosome 1A, $1 \mathrm{~B}$ and $1 \mathrm{D}$, respectively [38]. The genes at the three loci share a high percentage of homologous sequences. At each locus, one x-type and one y-type subunits are encoded. The composition and amount of HMW-GSs have a profound influence on the baking quality of wheat $[39,40]$. HMW-GS $1 B \times 14$ is encoded by the gene at the Glu-B1 locus. Several studies have shown that the $1 \mathrm{Bx} 14+1 \mathrm{By} 15$ subunit pair has a positive influence on the end use quality of wheat varieties [41]. More recently, the $1 B \times 14$ gene has been isolated and sequenced (GenBank accession: AY367771.1). A $1 B \times 14$ knockout mutant derived from an elite Chinese wheat variety Xiaoyan 54 through chemical mutagenesis was generated and characterized, providing an opportunity for identifying the biological function of $1 B \times 14$ [42]. We tried to generate transgenic lines with a $1 B \times 14$ over-expressed construct by microprojectile bombardment to assess the gene function, but introduction of this gene led to silence of several other homologous endogenous genes in the common wheat cv. Mianyang 19 [43].

Our long term goal is to elucidate the effect of specific proteins on wheat grain quality and end use. In this study, we first tested the possibility of employing BSMV vector to silence genes in wheat spikes or grains with the marker gene PDS encoding phytoene desaturase, an enzyme required for the biosynthesis of carotenoid pigments that protect chlorophyll from photobleaching. Silencing of $P D S$ can be visualized as white streaks resulting from photobleached chlorophyll [10]. After optimizing the locations and stages for VIGS in wheat 
spikes and grains, we chose to silence the $H M W-G S$ $1 B \times 14$ gene because the protein products have been shown by our group to participate in forming larger glutenin polymers and greatly contribute to dough strength [44]. We also chose to silence the entire family of $H M W-G S$ genes related to wheat gluten quality for testing the feasibility of BSMV-VIGS for functional analysis in wheat grains (Figure 1). The results in this study indicate that BSMV-VIGS system is a useful tool for functional analysis of genes expressed in wheat spikes and grains.

\section{Results}

\section{BSMV is able to induce gene silence in wheat spikes/grains}

To examine whether BSMV vector can induce gene silencing in wheat spikes and grains, we used the BSMV vectors carrying a 185-bp fragment of barley $P D S$ gene (designated as BSMV:PDS) [11,45] for the initial silencing experiment. Two winter wheat, cvs Xiaoyan 6 and Shaanyou 225, and a spring wheat, cv. Ningchun 16, were used in this experiment. To test the infectivity and the efficacy of BSMV-VIGS in all three wheat cultivars, we conducted a preliminary experiment at the seedling stage to silence the PDS gene. We inoculated ten seedlings of each wheat cultivar with BSMV:PDS and BSMV:00 (for only the BSMV genome without the target gene), respectively, onto the $2^{\text {nd }}$ fully expanded leaves of 10-day-old seedlings. Mosaic and chlorotic stripes were observed on the tip portions of the third leaves of all inoculated plants about 7 days post inoculation (dpi). Only the BSMV:PDS inoculated plants (10 out of 10) showed photobleaching starting from the base areas of the third leaves and extending throughout the length of the fourth leaves during $10 \sim 30$ dpi. Photobleaching was very rarely seen in the fifth leaves of all three cultivars (data not shown). No photobleaching was observed in the plants infected with BSMV:00. These observations indicated that the BSMV:PDS construct could systemically induce gene silencing in all three cultivars and efficiently induce $P D S$ gene silencing in these cultivars.

In order to investigate the effectiveness of BSMVVIGS in wheat spikes, endogenous PDS was again selected as a target to silence. We inoculated ten plants of each wheat cultivar on their spikes at heading stage by rubbing each spike five times with BSMV:PDS and BSMV:00, respectively. Unlike the progress of BSMV: PDS infection observed on leaves of wheat seedling, no mosaic symptoms and chlorosis were observed on wheat spikes by $13 \mathrm{dpi}$; only some ring-like or stripe symptoms were visible on the awns of some infected spikes. The symptoms of wheat spikes infected with BSMV:PDS were indistinguishable from those infected with BSMV:00 at $13 \mathrm{dpi}$ or earlier. However, photobleaching on the

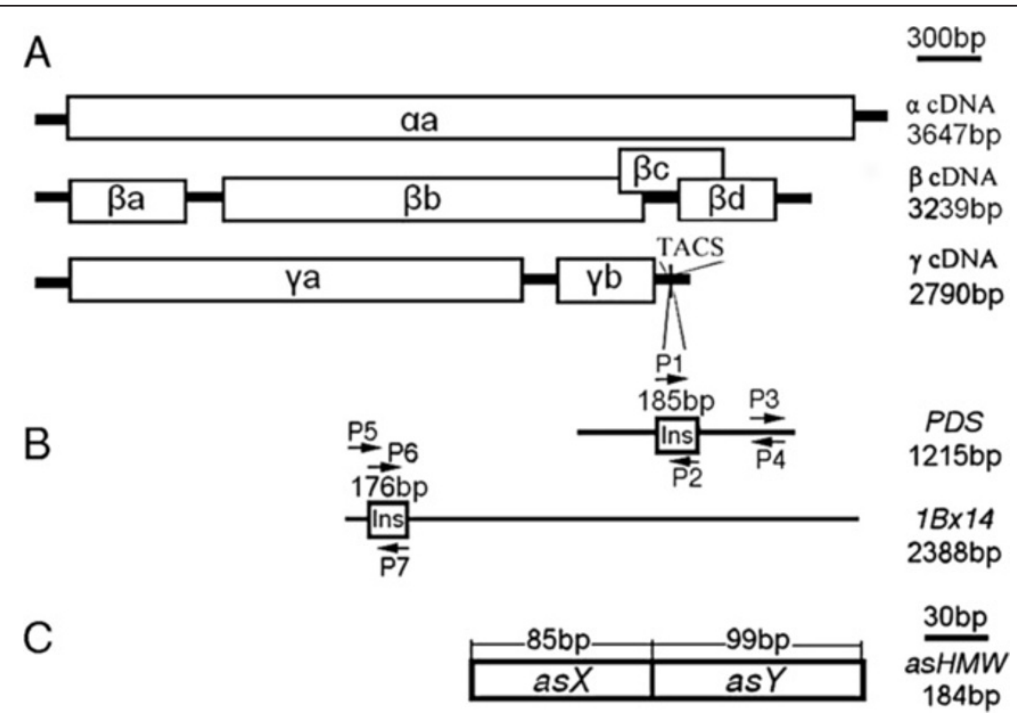

Figure 1 Schematic organization of the Barley stripe mosaic virus (BSMV) genomes and the inserts used for BSMV virus-induced-genesilencing (VIGS). (A) Genomic organization of the three BSMV components $\alpha, \beta$ and $\gamma$ drawn to scale of 300 bp. Open reading frames are indicated by boxes. The TA cloning site (TACS) designed for direct cloning of PCR products is positioned after the stop codon of the $\gamma b$ gene. (B) Schematic representation of full-length phytoene desaturase gene (PDS) and $1 B \times 14$ cDNAs (black line) drawn to the same scale as above. The 185-bp fragment of PDS and the 176-bp fragment of 1Bx14 CDNAs indicated by boxes are inserts for BSMV-VIGS. P1 and P2, P6 and P7 are primer sets for generating the VIGS construct BSMV:PDS and BSMV:1BX14, respectively. P3 and P4, P5 and P7 are primer sets for quantitative real-time RTPCR (qRT-PCR) analysis of PDS and 1BX14 transcripts, respectively. (C) Schematic representation of a 184-bp insert fragment of artificially synthesized sequence (asHMM) with one 85-bp sequence that is identical to most X-type glutenin subunit genes (asX) and one 99-bp sequence that is identical to most $y$-type genes (as Y), drawn to the scale of $30 \mathrm{bp}$. 
spikes infected with BSMV:PDS appeared after 13dpi, and persisted until 30dpi, while the spikes inoculated with BSMV:00 remained green during the same period (Figure 2A). Nine of the ten plants (90\%) inoculated with BSMV:PDS showed photobleaching throughout the entire wheat spike (Table 1), and the photobleaching persisted until 30 dpi (Figure 2A).

To confirm that the observed photobleaching was the result of $P D S$ silencing, we conducted quantitative realtime PCR (qRT-PCR) to measure the PDS transcript abundances in the spikes inoculated with BSMV:PDS at different time points. Surprisingly, a $25 \%$ reduction in PDS transcript abundance was detected as early as $2 \mathrm{dpi}$, but a remarkable reduction of PDS was detected between 8-13 dpi. From 4-30 dpi, the PDS mRNA level in spikes treated with BSMV:PDS was only about $60 \%$, or lower than the level in spikes with BSMV:00 treatment (Figure 2B). The most significantly bleached spikes were seen at $22 \mathrm{dpi}$, much later than the reduction of the PDS transcript level.

The effectiveness of VIGS in wheat grains was then investigated. Grains from BSMV:PDS infected spikes appeared photobleached only when their glumes were taken off and the grains were exposed directly under bright light. The phenotypes of the grains from the heads infected with BSMV:PDS or BSMV:00 at $22 \mathrm{dpi}$ are shown in Figure 3A with cultivar Xiaoyan 6 as a representative. Chlorosis occurred in the grains of BSMV: PDS infected heads at $22 \mathrm{dpi}$, while the grains of BSMV:00 inoculated control plants remained green, suggesting photobleaching of these seed coats was due to the silencing of the PDS gene. To confirm this, transcript abundances of the PDS gene in the photobleached and non-photobleached grains were measured by qRTPCR. The level of PDS transcript abundance in the chlorotic grains was reduced by $92 \%(\mathrm{P}<0.01)$, compared with the green ones (Figure $3 \mathrm{~B}$ ).

\section{Optimal conditions for efficient gene silencing in wheat spikes and grains}

Similar to leaf-rub inoculation applied to wheat seedlings $[1,11]$, spike-rub inoculation on the spikes at heading stage was also effective for gene silencing in spikes and grains. Syringe-injection inoculation onto the spikes

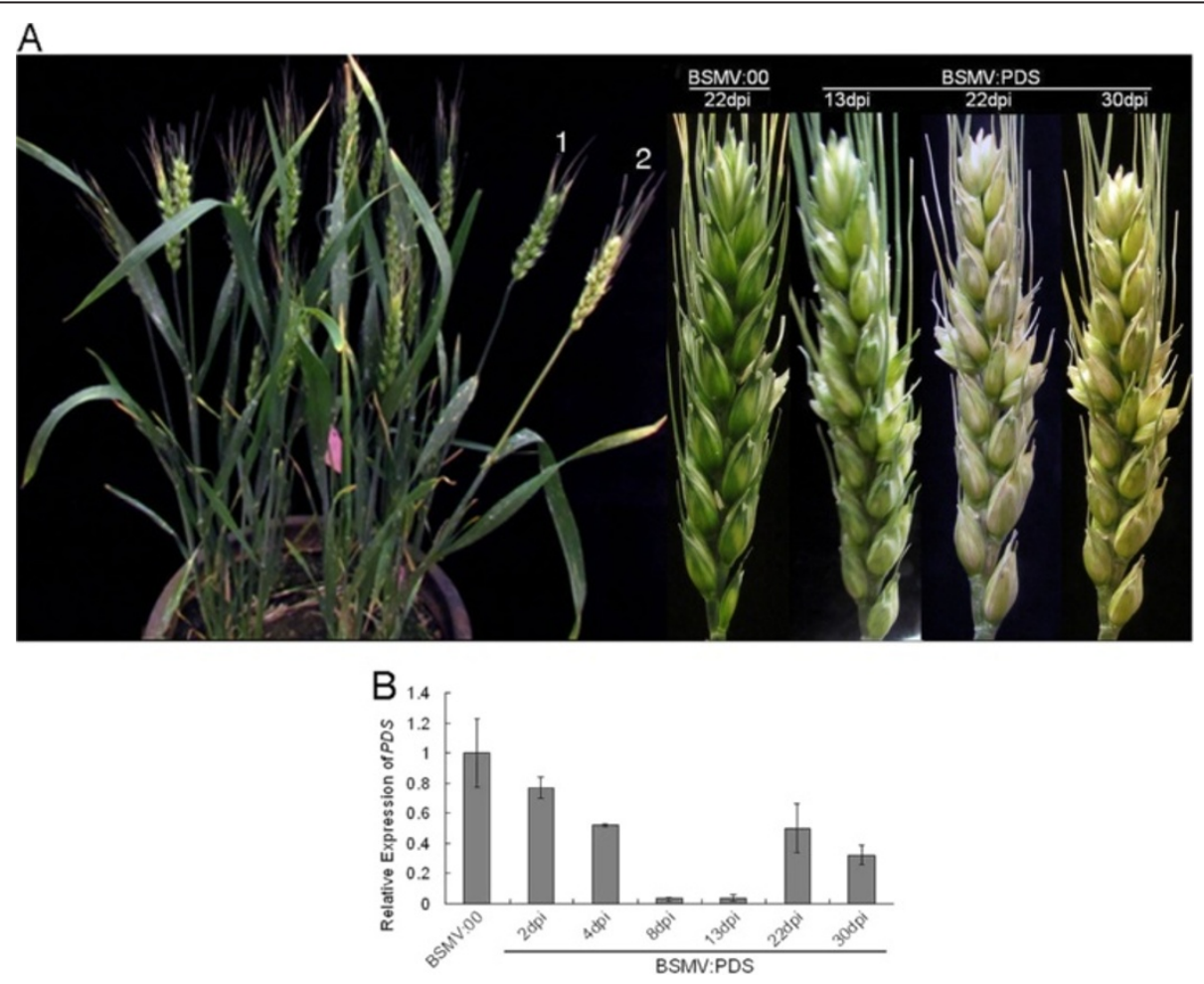

Figure 2 Silencing endogenous phytoene desaturase gene (PDS) in wheat spikes. Wheat cv. Xiaoyan 6 was infected with in vitro transcribed RNAs representing the $\alpha, \beta$ and $\gamma$ RNAs of BSMV:00 or $\alpha, \beta$ and $\gamma$ PDS RNAs of BSMV:PDS onto the spikes at the heading stage. (A) Left photograph indicates the phenotypes of wheat plants respectively infected with BSMV:00 (1) and BSMV:PDS (2) at 22 days post-inoculation (dpi); the right one is the spikes photographed at $13 \mathrm{dpi}, 22 \mathrm{dpi}$ and $30 \mathrm{dpi}$, respectively. The spikes shown are representative of different treated plants. (B) The relative expression levels of PDS in the wheat spikes inoculated with BSMV:PDS at 2, 4, 8, 13, 22 and 30 dpi are determined by quantitative real-time PCR (qRT-PCR) (normalization to actin) compared the BSMV:00 control inoculated with BSMV:PDS. Each column represents the mean of three samples, and error bars indicate the standard deviation. 
Table 1 Effectiveness of PDS silencing in the spikes of Xiaoyan 6 plants inoculated with BSMV:PDS at three different development stages

\begin{tabular}{|c|c|c|c|c|}
\hline \multirow{2}{*}{$\begin{array}{l}\text { Development } \\
\text { stage }\end{array}$} & \multirow{2}{*}{$\begin{array}{l}\text { Inoculation } \\
\text { location }\end{array}$} & \multirow{2}{*}{$\begin{array}{l}\text { No. of plants } \\
\text { inoculated }^{\mathrm{a}}\end{array}$} & \multicolumn{2}{|c|}{ No. of plants with photobleaching phenotypes ${ }^{b}$} \\
\hline & & & Partial photobleaching & Complete photobleaching \\
\hline \multirow[t]{2}{*}{ Booting } & Flag leaf & 10 & 8 & 1 \\
\hline & Spike & 10 & 2 & 0 \\
\hline \multirow[t]{2}{*}{ Heading } & Flag leaf & 10 & 4 & 4 \\
\hline & Spike & 10 & 0 & 9 \\
\hline \multirow[t]{2}{*}{ Flowering } & Flag leaf & 10 & 0 & 0 \\
\hline & Spike & 10 & 0 & 10 \\
\hline
\end{tabular}

${ }^{a}$ This experiment was conducted with three independent biological replicates, ten plants were inoculated for each condition.

${ }^{b}$ Numbers of plants with partial or complete photobleaching were reproducible in three biological replicates.

at heading stage was also tested, but this method failed to get results as consistent as spike-rub inoculation. Therefore, spike-rub inoculation was used in all silencing assays later. Because photobleached phenotypes of the spikes or grains in BSMV:PDS inoculated plants exhibited a consistent correlation with the reduction of PDS transcript abundances in our experiments,
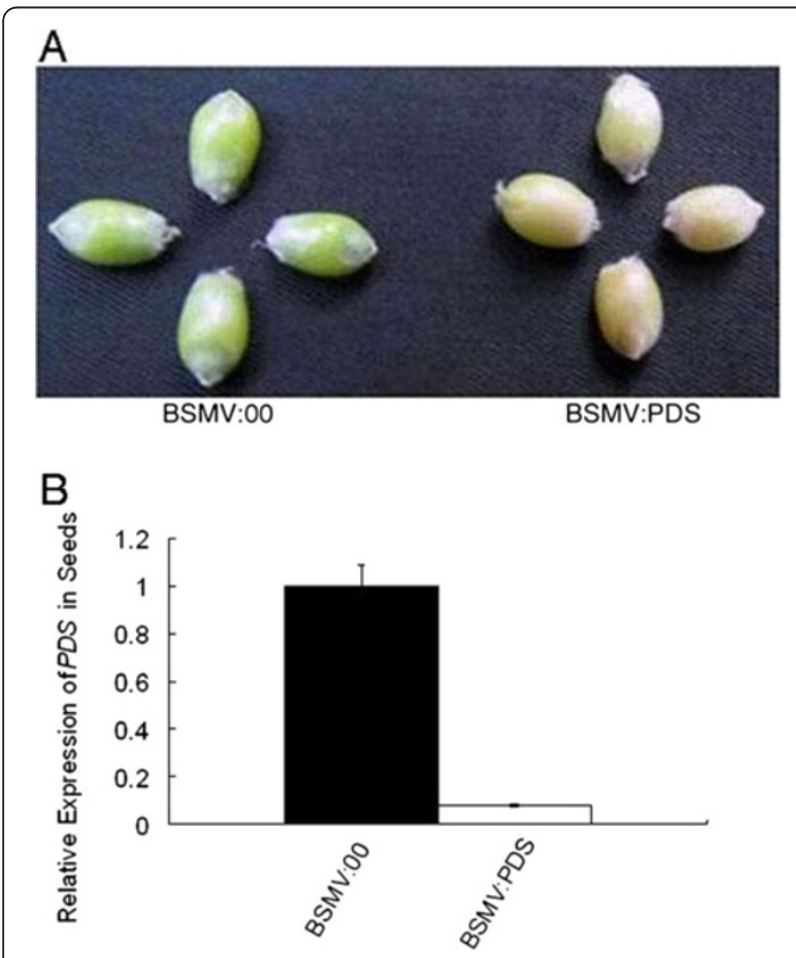

Figure 3 Silencing phytoene desaturase gene (PDS) in the grains of wheat cv. Xiaoyan 6 by BSMV-VIGS. (A) Left is four grains from a BSMV:00 inoculated spike and right is grains from a BSMV:PDS inoculated spike at 22 days post-inoculation (22dpi). The grains shown are representatives of ten different treated plants. (B) Transcript levels of PDS in these grains (Figure 3A) determined by quantitative real-time PCR (qRT-PCR). photobleaching was used as an indicator of PDS gene silencing in wheat spikes and grains.

To optimize conditions for efficient and stable silencing of genes in wheat spikes and grains, inoculation location and stage were determined by inoculating BSMV on flag leaves or spikes of ten plants for each wheat cultivar at three different development stages, i.e. booting, heading and flowering, respectively, by rubbing the in vitro synthesized BSMV RNAs three times on a flag leaf or five times on a spike. For simplicity, only the winter wheat cv. Xiaoyan 6 and the spring wheat cv. Ningchun 16 were tested at three different stages, and at each stage, the experiment included three independent biological replicates. As shown in Figure 4, at 22 dpi, photobleached spikes were observed in BSMV:PDS infected Xiaoyan 6 plants if BSMV:PDS was inoculated onto spikes at booting, heading or flowering stages. But if BSMV:PDS was inoculated onto flag leaves, photobleaching spikes appeared only in wheat plants inoculated at heading stage. These results were reproducible in three biological replicates. Figure 4 shows three reproducible phenotypes with different degrees of photobleaching, i.e. green spikes (no photobleaching), partially photobleached spikes (partial photobleaching) and uniform highly photobleached spikes (complete photobleaching). Effectiveness of BSMV-induced PDS silencing in wheat spikes was strongly influenced by the location of the inoculation and the stage of the plant when the inoculation was done. From heading to flowering stage, 90\% (9/10) $\sim 100 \%$ (10/10) of plants inoculated with BSMV:PDS onto spikes exhibited highly uniform photobleaching (Table 1). Similar results were also observed in wheat cv. Ningchun 16 (data not shown). We also attempted inoculation onto wheat spikes 10 days after flowering, but failed to achieve silenced phenotypes.

Taken together, inoculation onto wheat spikes from heading to flowering stage was optimal for efficient silencing of $P D S$ in wheat spikes. 


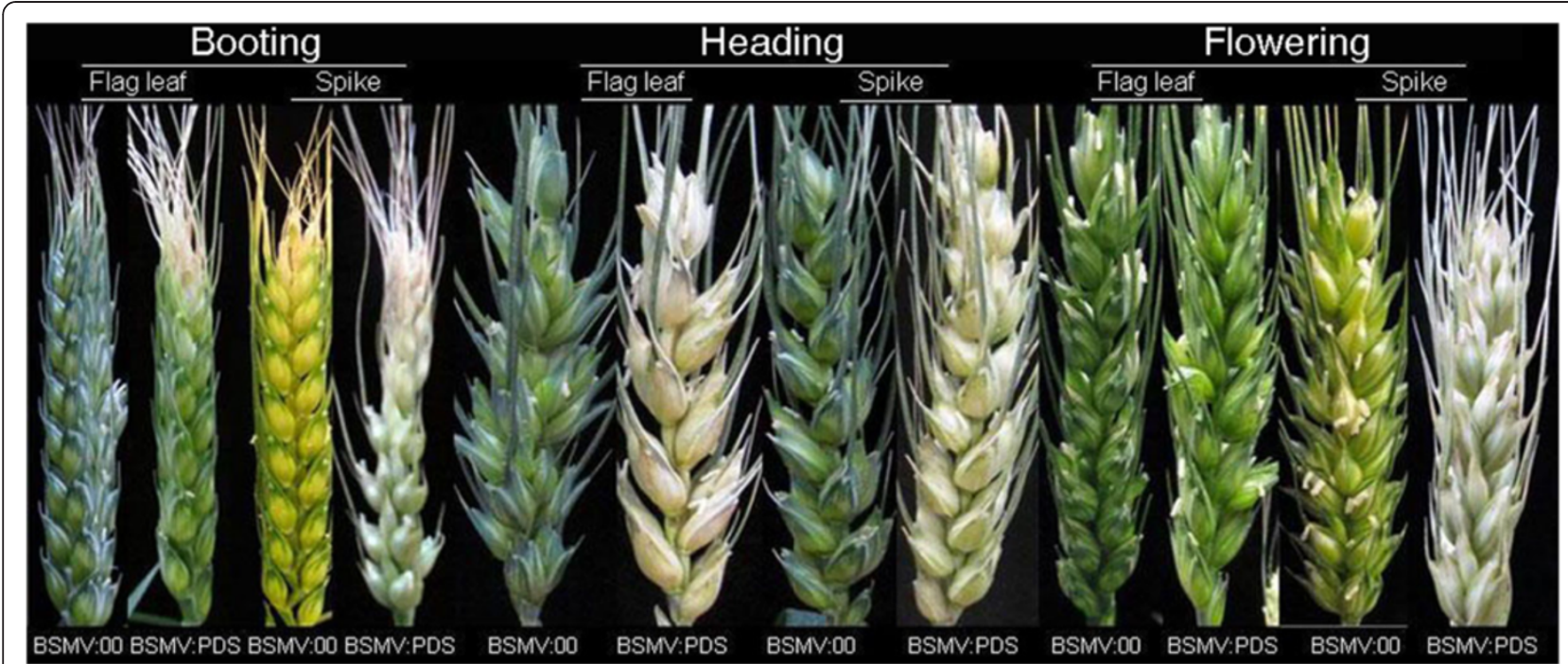

Figure 4 Phenotypes of the spikes from wheat cv. Xiaoyan 6 inoculated with BSMV:PDS or BSMV:00 constructs. The spikes shown are representatives of different treated plants and all spikes were collected at $22 \mathrm{dpi}$. Booting, Heading and Flowering above indicate the inoculation stage. Flag leaf or Spike on the top of each spike indicates the inoculation location. BSMV:PDS or BSMV:00 at the bottom indicates inoculation with BSMV:PDS or BSMV:00 constructs.

\section{Evaluation of biological function of the $1 B \times 14$ gene in gluten network formation in wheat grains using BSMV-VIGS}

After optimizing the BSMV-based VIGS system in wheat spikes/grains, we tried to explore the usefulness of the system for functional analysis of genes expressed in wheat grains. The $1 B \times 14$ gene (GenBank accession number AY367771.1) was chosen as a gene of interest tested in two wheat cultivars carrying 1Bx14, Xiaoyan 6 and Shaanyou 225. To make gene silencing as specific as possible, a 176-bp fragment of $1 B \times 14$ from the coding region (corresponding to the region of 98 to 273-bp downstream of the start codon) was inserted into the TA cloning site of the BSMV $\gamma$ vector to generate the construct BSMV:1Bx14 (Figure 1A and 1B). The 176-bp insert fragment possesses approximately $60-82 \%$ identity to the DNAs of the HMW-GS gene $1 A x 1,1 B y 15,1 D x 2$ and $1 D y 12$ in wheat cvs Xiaoyan 6 and Shaanyou 225 (Additional file 1).

Ten plants of each wheat cultivar were inoculated with BSMV:00 and BSMV:1Bx14 respectively on the spikes at flowering stage. The grains in the middle of the infected spikes were collected at 15, 20, 25 and 30 dpi for RNA isolation. Transcript abundances of $1 B \times 14$ were measured in all the grain RNA samples by qRT-PCR. The data showed that the transcript levels of $1 B \times 14$ decreased by about $97 \%$ at $15 \mathrm{dpi}$ and $85 \%$ at $20 \mathrm{dpi}$ in the grains of BSMV:1Bx14 infected spikes compared with that of the BSMV:00 infected control. Actin was used as an internal control. The reduction persisted until at least $25 \mathrm{dpi}$ (Figure 5). These data were similar to the results of PDS silencing described above. The amount of HMW-GS
1Bx14 of the 1Bx14-silenced grains of Xiaoyan 6 and Shaanyou 225 was detectably decreased on Sodium dodecyl sulphate-polyacrylamide gel electrophoresis (SDS-PAGE) (Figure 6A and 6B). The scanning profiles of the SDS-PAGE gels shown in Figure $6 \mathrm{~A}$ and $6 \mathrm{~B}$ shows the quantitative reduction of protein level; i.e. the peak of HMW-GS 1Bx14 in the 1Bx14-silenced grains was about $64 \%$ reduced in cultivar Xiaoyan 6 (Figure $6 \mathrm{C}$ ) and $67 \%$ in Shaanyou 225 (Figure 6D) compared with that in the controls, respectively. The protein levels of $1 B \times 14$ were not reduced as much as the mRNA levels (Figure $6 \mathrm{E}$ and $6 \mathrm{~F}$ ).

To evaluate the impact of $1 B \times 14$ knockdown in the formation of wheat gluten network, total proteins (TP), total glutenin polymer(TGP) and glutenin macropolymeric protein (GMP) of the grains from BSMV:Bx14 and BSMV:00 infected spikes were extracted and

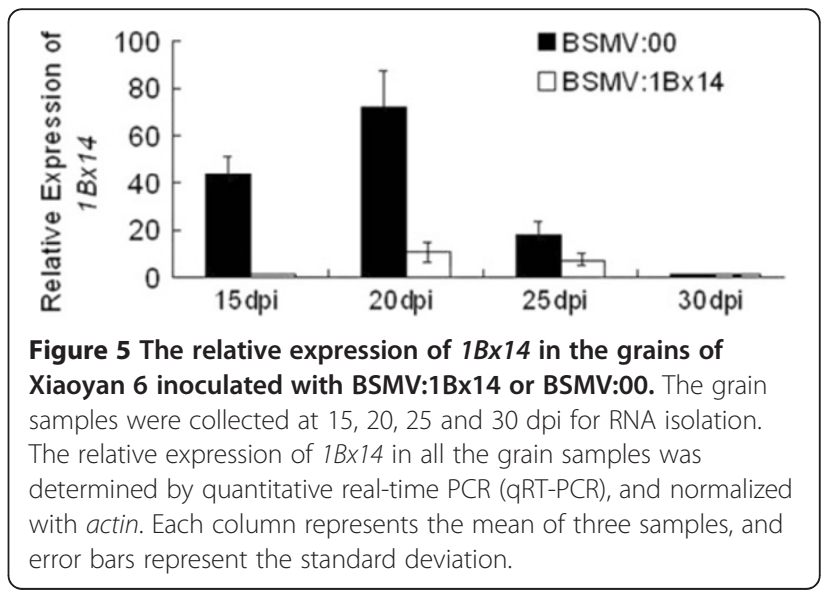



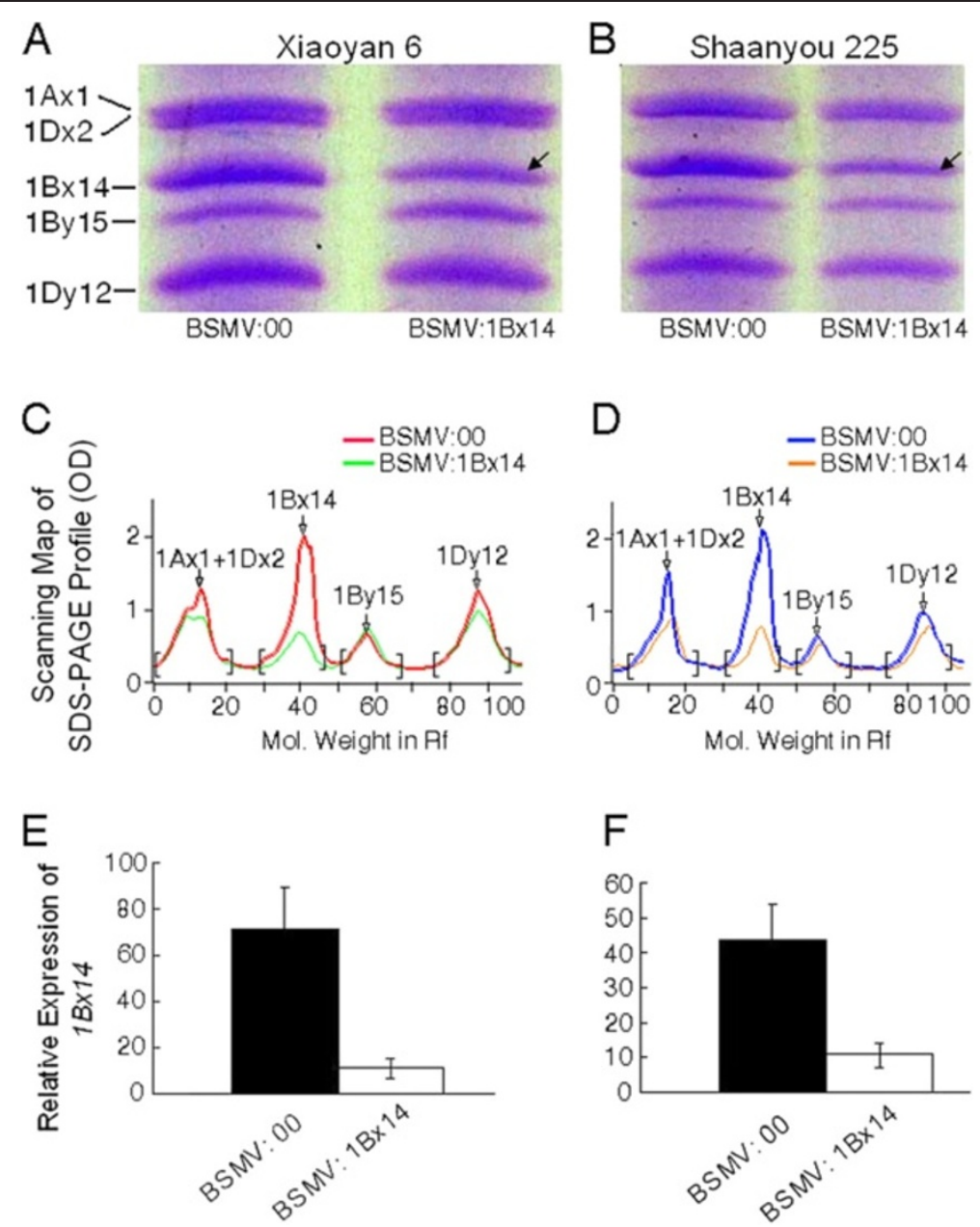

Figure 6 The protein and mRNA levels of 1Bx14 in the grains of BSMV:1Bx14 infected spikes. Grain samples were collected at 20dpi from each wheat CV. infected with BSMV:1Bx14 or BSMV:00, and each of the grains was divided into two parts, one used for Sodium dodecyl sulphatepolyacrylamide gel electrophoresis (SDS-PAGE) and the other for quantitative real-time PCR (qRT-PCR) analysis. (A) and (B) SDS-PAGE of HMW-GSS in the grain from cultivars Xiaoyan 6 or Shaanyou 225 inoculated with BSMV:00 or BSMV:1Bx14, respectively. Arrows indicate the reduced HMWGS 1Bx14. (C) and (D) The scanning profiles of SDS-PAGE maps shown in Figure 6 and 6B. (E) and (F) QRT-PCR analysis of the relative expression of $1 B \times 14$ in the same grain as in Figure $6 \mathrm{~A}$ or $6 \mathrm{~B}$.

quantified by micro-Kjeldahl method, respectively. The quantity of GMP, TGP or TP in the grains of $1 B \times 14-$ silenced plants were significantly decreased, compared with that in BSMV:00 infected controls in both Xiaoyan 6 and Shaanyou 225. The ratio of GMP to TP or the percentage of GMP in TP was significantly reduced (Table 2), indicating that HMW-GS 1 Bx14 is one of the major components participating in the formation of glutenin macropolymers in wheat grains. These results are consistent with our previous conclusion, suggesting the usefulness of BSMV-VIGS system for the functional analysis of genes expressed in wheat grains.

\section{Silencing of all HMW-GS gene family members in wheat grains via BSMV-VIGS system}

The successful silencing of the $1 B \times 14$ gene by the BSMV-VIGS system encouraged us to silence all the
$H M W-G S$ gene family members in wheat grains. A BSMV-derived construct carrying a 184-bp fragment of artificially assembled sequence (asHMW) was developed and named as BSMV:HMW. The 184-bp fragment contained one 85 -bp sequence highly homologous to most of the $\mathrm{x}$-type glutenin subunit genes (asX) and one 99bp sequence identical to most of the y-type glutenin subunit genes (as $Y$ ) (Figure 1C). Nucleotide sequence alignment of the as $X$ or the as $Y$ with the corresponding elements in other $\mathrm{x}$-typeor $\mathrm{y}$-type $H M W-G S$ genes in wheat was shown in Additional file 2.

All three wheat cultivars mentioned above were tested in this experiment. Ten plants of each wheat cultivar were inoculated with BSMV:HMW or BSMV:00 on the spikes at flowering stage. Silencing of $H M W-G S$ genes was monitored by SDS-PAGE on protein levels due to the lack of primers specific to individual target genes for 
Table 2 The mean values of TP, TGP and GMP in the grains from 1Bx14-silenced or control plants (infected with BSMV:00)

\begin{tabular}{|c|c|c|c|c|c|}
\hline Cultivar & BSMV Construct & TP (\%) & TGP (\%) & GMP (\%) & GMP/TP (\%) \\
\hline \multirow[t]{2}{*}{ Xiaoyan 6} & BSMV:00 & $16.50 \pm 0.06 \mathrm{~A}$ & $9.23 \pm 0.07 \mathrm{~A}$ & $8.34 \pm 0.06 A$ & $50.55 \pm 0.51 A$ \\
\hline & BSMV:1Bx14 & $15.25 \pm 0.04 \mathrm{~B}$ & $8.41 \pm 0.08 B$ & $6.82 \pm 0.12 B$ & $44.73 \pm 2.93 B$ \\
\hline \multirow[t]{2}{*}{ Shaanyou 225} & BSMV:00 & $17.74 \pm 0.07 \mathrm{~A}$ & $9.58 \pm 0.10 \mathrm{~A}$ & $7.95 \pm 0.04 \mathrm{~A}$ & $44.81 \pm 1.89 a$ \\
\hline & BSMV:1Bx14 & $15.18 \pm 0.13 B$ & $8.50 \pm 0.11 B$ & $6.49 \pm 0.09 B$ & $42.73 \pm 0.75 b$ \\
\hline
\end{tabular}

The mean values resulted from three independent biological replicates.

TP, TGP and GMP indicate total proteins, total glutenin polymers, and glutenin macropolymeric proteins, respectively.

Means with different capital letters indicate significantly different at $P<0.01$ level.

Means with different small letters are significantly different at $\mathrm{P}<0.05$ level.

real-time PCR. As shown in Figure 7, the amount of each $\mathrm{x}$-type or $\mathrm{y}$-type HMW-GS extracted from the seeds of the BSMV:HMW infected spikes of Ningchun 16 showed detectable decrease compared with the BSMV:00 treated spikes, indicating that all the $H M W$ GS genes $1 A x 2 *, 1 B x 17,1 B y 18,1 D x 5$ and $1 D y 10$, were down-regulated in the seeds of BSMV:HMW infected spikes of Ningchun 16. However, in the seeds of BSMV: HMW infected spikes of Xiaoyan 6 and Shaanyou 225, no apparent reduction in amount of HMW-GS was observed, suggesting that all the $H M W-G S$ gene family members were not efficiently silenced.

\section{Discussion}

Despite the widespread use of VIGS in seedling plants, its application in reproductive tissues of plants is rather limited. In the review by Scofield \& Nelson [46], the authors mentioned that VIGS could be achieved in the flag leaves and floral organs by inoculating upper leaves of older wheat plants with the BSMV RNAs, citing unpublished data without further details or documentation. In wheat, to date, there is no report of the application of VIGS in developing seeds. In this study, we report, for the first time, the successful application of BSMV-based VIGS for gene knockdown in wheat spikes and grains and its application in functional analysis of HMW-GSencoding gene $1 B \times 14$. Unlike Cucumber mosaic virus
(CMV)- or Apple latent spherical virus (ALSV)-vector for VIGS in soybean (Glycine max), with which inoculation onto the first leaf at the seedling stage or two cotyledons at emergence stage of soybean plants could effectively lead to gene silence in seeds [28,29], inoculation with BSMV:PDS recombinant virus onto the first leaf of wheat or barley plants at the seedling stage led to the most efficient PDS silencing in the third leaf, but the silence effect largely disappeared before the onset of flowering in nearly all plants. Occasionally, some degree of photobleaching was observed in the flag leaf and some of the heads [47]. When barley or wheat were infected with the BSMV:PDS construct, the duration of silencing lasted only about 4 weeks post-inoculation $[11,47]$.

Considering both the duration of effective BSMVbased VIGS and the temporal and spatial expression of some genes related to wheat quality or yield, the optimal inoculation conditions for VIGS in wheat spikes and grains are needed to be determined for efficient gene silencing in wheat productive organs. In this study, we established a protocol for effective knockdown of genes expressed in wheat spikes and developing seeds using BSMV-based VIGS. We found that efficiency of BSMVinduced gene silencing varied greatly with the locations and the stages of inoculation, and inoculation with BSMV on wheat spikes from heading to flowering stage

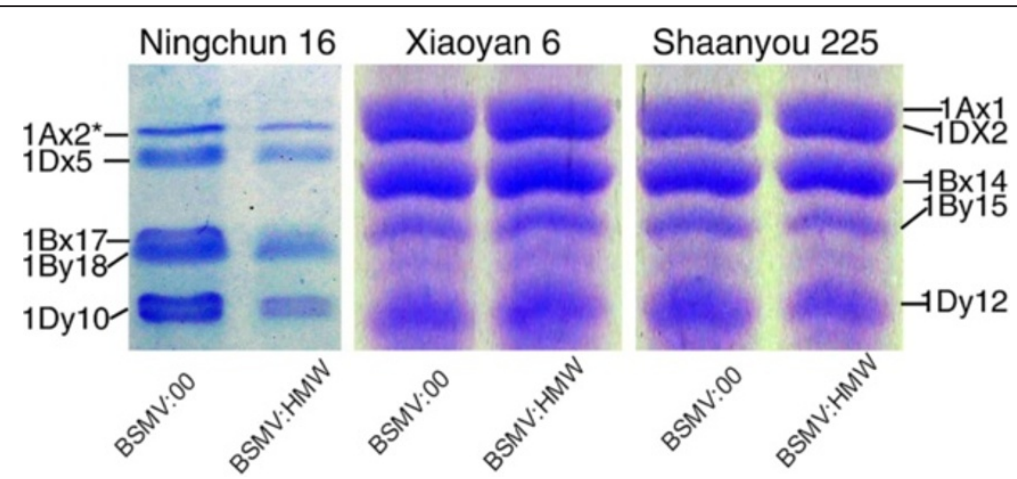

Figure 7 The HMW-GS in the grains of BSMV:HMW or BSMV:00 infected wheat spikes analyzed by SDS-PAGE. All three wheat cultivars Ningchun 16, Xiaoyan 6 and Shaanyou 225 were used in this experiment. Grain samples were collected at 30dpi from wheat plants of each cultivar infected with BSMV:1Bx14 or BSMV:00. 
by spike-rubbing five times showed the most effective silencing of PDS in wheat spikes (Table 1). Since gene silencing with BSMV-based VIGS vector is generally transient, inoculation on spikes at the appropriate time is crucial for knockdown of genes expressed only in developing seeds.

Compared with BSMV-VIGS experiments with barley or wheat seedlings, the main visual differences distinguishing BSMV-VIGS in wheat spikes are viral symptoms, the phenotypes of plants with gene silencing, and the time period of the effect. Wheat plants inoculated with BSMV:PDS at the seedling stage exhibited patches of lesion in the leaf above the inoculated one[11]. However, for wheat plants infected with BSMV:PDS onto spikes, only ring-like or stripe symptoms appeared on the awns of infected spikes. As for the phenotype of PDS silencing, both leaves and spikes showed apparent photobleaching. However, photobleaching in the leaf often did not cover the entire width of the leaf and was often confined to narrow stripes parallel to the leaf veins [10], while photobleaching in the spike extended to the entire spike (Figure 2A and Figure 4). With regard to the effective time period of BSMV-VIGS, evident photobleaching initially appeared in the third and fourth leaves of the barley seedlings by $7 \mathrm{dpi}$, and leaves that emerged after 21 dpi were unlikely to have photobleaching when BSMV:PDS inoculation was done on the first leaves [10]. However, our results showed that, when wheat spikes were infected with BSMV:PDS, visual photobleaching appeared on the spikes after $13 \mathrm{dpi}$, and persisted until 30 dpi. The qRT-PCR data revealed that PDS transcript abundances in BSMV:PDS infected spikes reduced by about $25 \%$ at $2 \mathrm{dpi}, 95 \%$ between $8 \sim 13 \mathrm{dpi}$, and $45 \%$ at $22 \mathrm{dpi}$, compared with those in spikes inoculated with BSMV:00 (Figure 2B). But the most remarkable photobleaching was observed at $22 \mathrm{dpi}$, much later than the reduction of $P D S$ transcript. The reduction in PDS mRNA levels began earlier and lasted longer than the period of photobleaching (Figure 2). Notably, PDS transcript abundances in BSMV:PDS infected spikes were prone to increase at $22 \mathrm{dpi}$ and $30 \mathrm{dpi}$. This is due to the instability of recombinant BSMV:PDS leading to deletion of PDS sequences from the virus vector (data not shown). These conditions were also reported previously by Bruun-Rasmussen et al. [47].

After optimization of conditions, we also successfully silenced the gene $1 B \times 14$ that encodes storage protein in wheat endosperm. The correlated reduction in the levels of the mRNA and the protein of HMW-GS 1Bx14 suggested VIGS-treatment can effectively knockdown genes expressed in developing seeds (Figure 6). Notably, the reduction in mRNA-level and in protein level of $1 B \times 14$ in Figure 6 was not comparable. We speculate that the reason is that the protein abundances shown in
Figure $6 \mathrm{~A}$ and $6 \mathrm{~B}$ were the consequence of about a 10 day-accumulation because $H M W-G S$ genes initially expressed 9 12 days after flowering, while the transcript abundances shown in Figure $6 \mathrm{E}$ and $6 \mathrm{~F}$ were the mRNA level of $1 B \times 14$ in the 1Bx14-silenced grains at 20dpi due to the short lifetime of mRNA. The peak of gene silencing induced by BSMV was at 20dpi according to qRTPCR results in the BSMV:1Bx14 time course study (Figure 5).

However, when silencing the entire $H M W-G S$ gene family in wheat grains with the BSMV:HMW construct, the results were not the same among the three wheat cultivars. All the $H M W-G S$ genes $1 A x 2^{*}, 1 B x 17,1 B y 18$, $1 D \times 5$ and $1 D y 10$ in spring wheat $\mathrm{cv}$. Ningchun 16 were detectably down-regulated in the seeds of BSMV:HMW infected spikes, but no apparent reduction was detected in the seeds from BSMV:HMW infected spikes of cultivars Xiaoyan 6 and Shaanyou 225. Scofield et al. [11] also reported that only $21 \%$ of the wheat plants and $16 \%$ of the barley plants displayed any detectable photobleaching when infected with the BSMV:PDSas construct carrying an 80-bp PDS4as derivative fragment, and no photobleaching was observed in any of the plants infected with the 40-bp PDS4as derivative. The sizes of the inserts greatly affect the efficiency of BSMV induced gene silence. Therefore, we think that the inconsistency among the three wheat cultivars for silencing $H M W-G S$ gene combinations may be due to the sizes of insertsas $X$ (85-bp) plus as $Y$ (99-bp) were not long enough for induction of efficient silencing.

It has been postulated based on early genetic studies $[34,40]$ that the composition and the amount of HMWGS in the grains can greatly affect gluten strength and thereby the end use qualities of both tetraploid and hexaploid wheat. The observation of significant alteration in the structure of gluten complex and the processing properties of wheat grains in a transgenic line that over-expresses a single HMW glutenin subunit reinforces this postulation [48]. However, more systematic analyses of the direct effects of $H M W-G S$ genes on grain properties are difficult due to technical difficulties in development of an ideal transgenic line that has the target $H M W-G S$ gene over-expressed without affecting other endogenous genes' expression in wheat grains. There have been many efforts in developing transgenic wheat lines to confirm the function of $H M W-G S$ genes, but most of them could not reach the final stage due to very low transformation efficiency and un-intended side effects in the transgenic wheat lines generated. For example, introduction of a construct overexpressing the gene $1 A x 1$ into a commercial spring bread wheat resulted in the inactivation of the $1 A \times 2 *$ allele. Transformation of constructs overexpressing both $1 A x 1$ and $1 D \times 5$ resulted in the silencing of all other $\mathrm{HMW}$ 
glutenin subunits [49]. The technical difficulties and phenotypic complication associated with transgenic approaches make the development of VIGS-based techniques to silence genes in grains more useful and urgent. In this study, we successfully silenced the $1 B \times 14$ gene, which is highly expressed in seeds of wheat cvs Xiaoyan 6 and Shaanyou 225 (Figure 6E and 6B). Silencing of $1 B \times 14$ led to a significant decrease in the quantity of GMP and the percentage of glutenin macropolymeric protein in total proteins (GMP/TP) of the grains (Table 2), indicating that HMW-GS 1 Bx14 plays very important roles in the formation of glutenin macropolymers (or wheat gluten network). By using purified HMW-GS 1Bx14 as a supplement to base flour to make dough and test its functional properties, our group found that incorporation of the HMW-GS increased the quantity of glutenin macropolymeric protein (GMP) in the dough and enhanced the dough strength [44]. The present results further support this conclusion. Unexpected was that a reduction of $7 \%$ 9\% in the total protein content was detected in grains of $1 B \times 14$-silenced plants, although an individual glutenin subunit accounts for only about $2 \%$ of total grain proteins. The effect of $1 B \times 14$ silencing on total proteins needs to be further investigated. To our knowledge, this is the first report of knockdown genes expressed in wheat developing seeds with recombinant BSMV. The establishment of this effective approach for gene knockdown in developing seeds will allow us to dissect the genetic pathways that control seed development, grain quality and pathogen defense in grain tissue of hexaploid wheat; it will also provide an important reference for silencing genes in spikes or grains of other monocotyledonous species by VIGS.

\section{Conclusions}

We first demonstrated the feasibility of using BSMV for gene silencing in wheat spikes or grains with $P D S$ as a marker gene. We determined that inoculation with BSMV onto wheat spikes from heading to flowering stage by spike-rub five times was the optimal condition for silencing $P D S$ in wheat spikes. In addition, we successfully silenced $H M W-G S$ gene $1 B x 14$ expressing in the developing seeds through the established BSMVVIGS approach. The BSMV-VIGS system in spikes and grains will be very useful in future research on functional identification of genes contributing to grain quality and controlling the metabolic networks in seed development of wheat.

\section{Methods}

\section{Plant material}

Three hexaploid wheat (T. aestivum L.) cultivars, two winter wheat cvs Xiaoyan 6 and Shaanyou 225, and one spring wheat cv. Ningchun 16, were used in the experiments. The two winter wheats are elite cultivars with good quality, and both possess identical HMW glutenin subunit genes, i.e. $1 A x 1,1 B x 14,1 B y 15,1 D x 2$ and $1 D y 12$, while Ningchun 16 has HMW glutenin subunit genes $1 A x 2 \% 1 B x 17,1 B y 18,1 D x 5$ and 1Dy10. For VIGS experiments, all three cultivars were grown in a greenhouse with a day/night temperature regime of $20-25^{\circ} \mathrm{C} /$ $15-18^{\circ} \mathrm{C}$, a light period of $16 \mathrm{~h} / 8 \mathrm{~h}$ day/night, regulated with supplementary light, and watered as needed. The two winter wheat cultivars were exposed to a temperature of $4^{\circ} \mathrm{C}$ for 40 days to achieve complete vernalization, while the spring wheat cultivar was exposed to $4^{\circ} \mathrm{C}$ for 14 days at the two leaves stage. The temperature of the greenhouse was kept at a constant $22^{\circ} \mathrm{C}$ after the booting stage of the three cultivars.

\section{Construction of BSMV-derived vectors}

The BSMV vectors utilized in these experiments were obtained from Dr. Andrew O. Jackson at UC Berkeley [50]. The $\gamma$ vector was reconstructed to include PCRready cloning sites following a protocol modified from Holzberg et al. [10]. The plasmids utilized in the experiments of silencing PDS in wheat spikes/grains were described in Campbell [45]. In details, the BSMV $\gamma$ vector was digested with $\operatorname{Not} \mathrm{I} / \mathrm{PacI}$ and inserted the sequence of GGCCCCACTCATGACATGGCGTTAGCCATGGGAAGCTTGGAT, including two $X c m I$ restriction sites. The modified $\gamma$ vector (named the $\gamma$ PCR vector) was linearized with restriction enzyme XcmI to produce a TA cloning site for direct cloning of PCR products. Since a BSMV $\gamma$ RNA construct carrying a 185-bp fragment of the barley (Hordeum vulgare L.), the PDS gene in antisense orientation (BSMV:PDS4as) induced optimal silencing of PDS in wheat leaves as described previously [11], we used the BSMV:PDS4as for initial testing under our experimental conditions. For simplicity, the BSMV: PDS4as construct was named as BSMV:PDS and the BSMV-derived construct with no insert as BSMV:00 in our experiments.

The BSMV construct utilized to silence the $1 B \times 14$ gene, which carrying a 176-bp fragment of $1 B \times 14$ cDNA, was designed as BSMV:1Bx14 and constructed as follows: The 176-bp fragment of $1 B \times 14$ from the coding region (corresponding to the region of 98 to 273-bp downstream of the start point of translation) was generated by PCR amplification from the plasmids containing the cloned 1Bx14 gene with the forward primer P6:5'GCGAGCTCCGGAAGCGCG-3' and reverse primer P7: 5'- CGAAGGCGTAGTCTCGCTGGGG-3', and inserted into the $\gamma$ vector (Figure $1 \mathrm{~A}$ and $1 \mathrm{~B}$ ). The analysis of the identity between the 176-bp fragment and the fulllength of $H M W-G S$ gene $1 A x 1,1 D x 2,1 B x 14,1 B y 15$ and $1 D y 12$ in wheat cultivars Xiaoyan 6 and Shaanyou 
225 was conducted with the DNAMAN software (www. lynnon.com).

The BSMV construct carrying a 184-bp fragment of an artificially assembled sequence (asHMW) with one 85-bp sequence identical to most $\mathrm{x}$-type glutenin subunit genes (as $X)$ and one 99-bp sequence identical to y-type glutenin subunit genes (asY), named as BSMV:HMW, was generated (Figure 1C) and used to silence the entire $H M W-G S$ gene family in wheat grains. The BSMV: HMW was constructed as follows: The fragment containing an 85 -bp fragment of $1 B \times 14$ from the encoding region (corresponding to the region of 296 to 380-bp downstream of the start codon) and a 99-bp fragment of 1 By16 (GenBank accession number EF540765.1) from the coding region (corresponding to the region of 798 to 896-bp downstream of the start codon) were synthesized (by Sangon, Shanghai, China), and inserted into the $\gamma$ vector. The 85 -bp sequence shared a $90.59-100 \%$ similarity to the corresponding elements in all $x$-type $H M W-G S$ genes and the 99-bp sequence shared a $94.95-100 \%$ similarity to those in all y-type $H M W-G S$ genes (Additional file 2).

\section{In vitro transcription of viral RNAs and plant inoculation}

The procedures for in vitro transcription of viral RNAs were the same as described by Scofield et al. [11]. In vitro synthesized BSMV RNAs were rub-inoculated onto flag leaves or spikes at three development stages, i.e. booting, heading and flowering, respectively.

Ten plants/cultivar were infected with each of BSMV + target, and BSMV:00, respectively, with three biological replicates. Inoculation on flag leaves was performed as described by Scofield et al. [11], while inoculation onto spikes was conducted by 5 times sliding with three gently pinched fingers from base to tip of the spikes.

\section{Total RNA extraction and CDNA synthesis}

Total RNA was isolated from wheat spikelets or grains by using RNAiso-mate (TaKaRa, Dalian, China) and RNAiso Plus (TaKaRa, Dalian, China) followed by cold phenol/chloroform extraction three times. The quality and concentration of total RNA were determined with a Nanodrop ND-1000 spectrophotometer (Nano Drop Technologies, Wilmington, DE, USA). All the RNA samples were treated with RNase-free DNase I (TaKaRa, Dalian, China) prior to synthesizing cDNA as recommended by the manufacturer. For RT-PCR analysis of $P D S$ and $1 B \times 14$ transcript abundances, first-strand cDNA was synthesized using 500 ng of total RNA, oligo (dT) primer and MMLV reverse transcriptase (TaKaRa, Dalian, China).
For analysis of BSMV-VIGS in wheat spikes or grains, the spikelets or grains in the middle of BSMV infected spikes were collected at 2, 4, 8, 15, 20, 22 and 30dpi.

\section{Measurements of transcript abundances by qRT-PCR}

Expression of the genes targeted for silencing was quantified by comparative quantitative real-time PCR (qRTPCR). QRT-PCR was performed in triplicate for each RNA sample/primer combination. The amount of RNA in each reaction was normalized using primers specific for actin. The primer sequences used to detect each gene were as follows: actin forward, 5'-AAATCTGGCATCACACTTTCTAC-3'; actin reverse, 5'-GTCTCA AACATAATCTGGGTCATC-3';PDS forward P3, 5'-TGT CTTTAGCGTGCAAG-3', PDS reverse P4, 5'-GATG ATTTCGGTGTCACT-3'; $1 B x 14$ forward P5, 5'-TAA GCGCCTGGTCCTCTTTGCG-3', 1Bx14 reverse P7, 5'CGAAGGCGTAGTCTCGCTGGGG-3'. The positions of the primer set used for qRT-PCR are shown in Figure 1B. QRT-PCR was operated three times on iCycler iQTM Multi-Color Real Time PCR Detection System (Biorad, Hercules, CA, USA) using SYBR Green Master Mix (Biorad, www.bio-rad.com). The cycling conditions were as follows: $2 \mathrm{~min}$ at $95^{\circ} \mathrm{C}$, followed by 45 cycles of $30 \mathrm{~s}$ at $95^{\circ} \mathrm{C}, 30 \mathrm{~s}$ at $55^{\circ} \mathrm{C}$ and $30 \mathrm{~s}$ at $72^{\circ} \mathrm{C}$. In all cases, the relative expression of the targeted gene is presented as the expression level of this gene in silenced plants relative to that of the same gene in plants infected with BSMV:00, and the values of gene expression were the averages of three independent biological replicates. For each PCR, the specificity of the amplifications was validated and the threshold cycle above background was calculated using Bio-Rad iCycler software. PCR efficiency was close to $100 \%$. Relative quantification of the gene transcript abundances was carried out applying an improved $\Delta \Delta$ analysis [51]. Error bars in all figures showing qRT-PCR data indicated the standard deviations calculated from the original CT (cycle threshold) values. The P-values were estimated using hypothesis test (student test).

\section{Extraction of HMW-GSs in wheat seeds and analysis by SDS-PAGE}

To determine the efficacy of $1 B x 14$ silencing at protein level, grains in the middle of wheat spikes from BSMV:1Bx14, BSMV:HMW or BSMV:00 inoculated plants were collected at $20 \mathrm{dpi}$, respectively, and HMWGSs were extracted from one grain of each sample with 200ul solution $(50 \%(\mathrm{v} / \mathrm{v})$ 1-propanol, $0.625 \mathrm{~mol} / \mathrm{L}$ Tris$\mathrm{HCl}(\mathrm{pH}=6.8), 10 \%$ SDS, 2\% DDT, 20\% Glycerin and $0.2 \%$ Bromophenyl blue). Equal volumes $(20 \mu \mathrm{l})$ of each protein sample were loaded and separated by SDS-PAGE with $5 \%$ stacking and $12 \%$ resolving polyacrylamide. Each 
treatment was performed with three independent biological replicates.

\section{Measurement of total proteins, total glutenin polymeric proteins and glutenin macropolymeric proteins of wheat grains}

Each grain sample of approximate $0.2 \mathrm{~g}$ was milled and equipped with a $0.5 \mathrm{~mm}$ screen to obtain wholemeal flour. Total glutenin polymers free from monomeric proteins and glutenin macropolymeric proteins (50\% 1-propanol insoluble fraction) of each wholemeal flour sample were isolated as previously described by $\mathrm{Xu}$ et al. [44]. The protein contents of total glutenin polymer, glutenin macropolymer or wholemeal flour were determined by micro-Kjeldahl (Foss Tecator AB, Hoganas, Sweden) analysis. The amount of proteins was estimated as $\mathrm{N} \times 5.7$. Each treatment was performed with three independent biological replicates.

\section{Additional files}

Additional file 1: Identity of the 176-bp fragment of $1 B \times 14$ with the full-length of $H M W$-GS gene $1 A x 1,1 B \times 14,1 B y 15,1 D \times 2$ and $1 D y 12$ in wheat cultivars Xiaoyan 6 and Shaanyou 225.

Additional file 2: Nucleotide sequence alignment of the as $X$ or the as $Y$ with their corresponding elements in other $x$-type (upper region) or $y$-type (lower region) HMW-GS genes expressed in the wheat variety, respectively; as $X$ and $a s Y$ represent sequences highly homologous to most of all x-type or y-type HMW-GS genes, respectively. Nucleotides conserved in all sequences are represented by ${ }^{\prime *}$. The alignment was conducted using the Clustal W program.

\section{Authors' contributions}

MM carried out the VIGS, genomic analysis and QRT-PCR, created the figures, and ran the SDS-PAGE. YY supported the VIGS analysis and raised the plant material. LH provided the BSMV vectors, technical advice, and edited the manuscript. $M C$ participated in modification of the manuscript. $\mathrm{HZ}$ designed the experiments and coordinated their implementation. $\mathrm{MM}$ and $\mathrm{HZ}$ participated in drafting the manuscript. All authors read and approved the final manuscript.

\section{Authors' information}

MM, YY, and HZ: State Key Laboratory of Crop Stress Biology for Arid Areas, College of Life Sciences, Northwest A \& F University, Yangling, 712100, Shaanxi, China.

LH: Department of Plant Sciences \& Plant Pathology, Montana State University, Bozeman, MT59717, USA.

MC: USDA-ARS and Department of Entomology, Kansas State University, Manhattan, KS66506, USA.

\section{Acknowledgements \\ This work was financed by Natural Science Foundation of China (30871578). We would like to thank Jackie Campbell, a Ph.D student of Dr. Li Huang in the Department of Plant Sciences and Plant Pathology, Montana State University, for her suggestions and discussions in exploring the technical feasibility of using BSMV for gene silencing in wheat spikes or grains with the PDS marker gene.}

\section{Author details}

'State Key Laboratory of Crop Stress Biology for Arid Areas, Yangling, Shaanxi 712100, China. ${ }^{2}$ College of Life Sciences, Northwest A \& F University, Yangling, Shaanxi 712100, China. ${ }^{3}$ Department of Plant Sciences \& Plant Pathology,
Montana State University, Bozeman MT59717, USA. ${ }^{4}$ USDA-ARS and Department of Entomology, Kansas State University, Manhattan KS66506, USA.

Received: 25 March 2012 Accepted: 28 June 2012

Published: 10 August 2012

\section{References}

1. Cakir C, Gillespie ME, Scofield SR: Rapid Determination of Gene Function by Virus-induced Gene Silencing in Wheat and Barley. Crop Sci 2010, 50:77-84.

2. Eid J, Fehr A, Gray J, Luong K, Lyle J, Otto G, Peluso P, Rank D, Baybayan P, Bettman $B$, et al: Real-time DNA sequencing from single polymerase molecules. Science 2009, 323:133-138.

3. Ansorge WJ: Next-generation DNA sequencing techniques. N Biotechnol 2009, 25:195-203.

4. Kaiser BN, Rawat SR, Siddiqi MY, Masle J, Glass AD: Functional analysis of an Arabidopsis T-DNA "knockout" of the high-affinity NH4(+) transporter AtAMT1;1. Plant Physiol 2002, 130:1263-1275.

5. Weigel D, Ahn JH, Blazquez MA, Borevitz JO, Christensen SK, Fankhauser C, Ferrandiz C, Kardailsky I, Malancharuvil EJ, Neff MM, et al: Activation tagging in Arabidopsis. Plant Physiol 2000, 122:1003-1013.

6. Ruiz MT, Voinnet O, Baulcombe DC: Initiation and maintenance of virusinduced gene silencing. Plant Cell 1998, 10:937-946.

7. Constantin GD, Krath BN, MacFarlane SA, Nicolaisen M, Johansen IE, Lund OS: Virus-induced gene silencing as a tool for functional genomics in a legume species. Plant J 2004, 40:622-631.

8. Dalmay T, Hamilton A, Mueller E, Baulcombe DC: Potato virus $\mathrm{X}$ amplicons in arabidopsis mediate genetic and epigenetic gene silencing. Plant Cell 2000, 12:369-379.

9. Liu YL, Schiff M, Dinesh-Kumar SP: Virus-induced gene silencing in tomato. Plant J 2002, 31:777-786

10. Holzberg S, Brosio P, Gross C, Pogue GP: Barley stripe mosaic virusinduced gene silencing in a monocot plant. Plant J 2002, 30:315-327.

11. Scofield SR, Huang L, Brandt AS, Gill BS: Development of a virus-induced gene-silencing system for hexaploid wheat and its use in functional analysis of the Lr21-mediated leaf rust resistance pathway. Plant Physiol 2005, 138:2165-2173.

12. Ding XS, Schneider WL, Chaluvadi SR, Mian MAR, Nelson RS Characterization of a Brome mosaic virus strain and its use as a vector for gene silencing in monocotyledonous hosts. Mol Plant Microbe In 2006, 19:1229-1239.

13. Ratcliff $F$, Harrison $B D$, Baulcombe $D C$ : A similarity between viral defense and gene silencing in plants. Science 1997, 276:1558-1560.

14. Robertson D: VIGS vectors for gene silencing: Many targets, many tools. Annu Rev Plant Biol 2004, 55:495-519.

15. Brodersen $P$, Voinnet $O$ : The diversity of RNA silencing pathways in plants. Trends Genet 2006, 22:268-280.

16. Burch-Smith TM, Anderson JC, Martin GB, Dinesh-Kumar SP: Applications and advantages of virus-induced gene silencing for gene function studies in plants. Plant J 2004, 39:734-746.

17. Schwach F, Vaistij FE, Jones L, Baulcombe DC: An RNA-dependent RNA polymerase prevents meristem invasion by potato virus $\mathrm{X}$ and is required for the activity but not the production of a systemic silencing signal. Plant Physiol 2005, 138:1842-1852.

18. Voinnet O, Lederer C, Baulcombe DC: A viral movement protein prevents spread of the gene silencing signal in Nicotiana benthamiana. Cell 2000, 103:157-167.

19. Kumagai MH, Donson J, Dellacioppa G, Harvey D, Hanley K, Grill LK: Cytoplasmic Inhibition of Carotenoid Biosynthesis with Virus-Derived Rna. Proc Natl Acad Sci USA 1995, 92:1679-1683.

20. Ratcliff FG, MacFarlane SA, Baulcombe DC: Gene silencing without DNA: RNA-mediated cross-protection between viruses. Plant Cell 1999, 11:1207-1215.

21. Zhang C, Ghabrial SA: Development of Bean pod mottle virus-based vectors for stable protein expression and sequence-specific virusinduced gene silencing in soybean. Virology 2006, 344:401-411.

22. Purkayastha A, Mathur S, Verma V, Sharma S, Dasgupta I: Virus-induced gene silencing in rice using a vector derived from a DNA virus. Planta 2010, 232:1531-1540. 
23. Chen JC, Jiang CZ, Gookin TE, Hunter DA, Clark DG, Reid MS: Chalcone synthase as a reporter in virus-induced gene silencing studies of flower senescence. Plant Mol Biol 2004, 55:521-530.

24. Lin Z, Hong Y, Yin M, Li C, Zhang K, Grierson D: A tomato HD-Zip homeobox protein, LeHB-1, plays an important role in floral organogenesis and ripening. Plant J 2008, 55:301-310.

25. Fu DQ, Zhu BZ, Zhu HL, Jiang WB, Luo YB: Virus-induced gene silencing in tomato fruit. Plant J 2005, 43:299-308.

26. Cai $X$, Wang $C, X u Y, X u$ Q, Zheng Z, Zhou X: Efficient gene silencing induction in tomato by a viral satellite DNA vector. Virus Res 2007 , 125:169-175.

27. del Rosario Abraham-Juarez M, del Carmen Rocha-Granados M, Lopez MG, Rivera-Bustamante RF, Ochoa-Alejo N: Virus-induced silencing of Comt, pAmt and Kas genes results in a reduction of capsaicinoid accumulation in chili pepper fruits. Planta 2008, 227:681-695.

28. Nagamatsu A, Masuta C, Senda M, Matsuura H, Kasai A, Hong JS, Kitamura K Abe J, Kanazawa A: Functional analysis of soybean genes involved in flavonoid biosynthesis by virus-induced gene silencing. Plant Biotechnol J 2007, 5:778-790

29. Yamagishi N, Yoshikawa N: Virus-induced gene silencing in soybean seeds and the emergence stage of soybean plants with Apple latent spherical virus vectors. Plant Mol Biol 2009, 71:15-24.

30. Hein I, Barciszewska-Pacak M, Hrubikova K, Williamson S, Dinesen M, Soenderby IE, Sundar S, Jarmolowski A, Shirasu K, Lacomme C: Virusinduced gene silencing-based functional characterization of genes associated with powdery mildew resistance in barley. Plant Physiol 2005 138:2155-2164.

31. Tai YS, Bragg J: Dual Applications of a Virus Vector for Studies of Wheat-Fungal Interactions. Biotechnology 2007, 6:288-291.

32. Zhang L, Lavery L, Gill U, Gill K, Steffenson B, Yan GP, Chen XM, Kleinhofs A: A cation/proton-exchanging protein is a candidate for the barley NecS1 gene controlling necrosis and enhanced defense response to stem rust. Theor Appl Genet 2009, 118:385-397.

33. Pacak A, Geisler K, Jorgensen B, Barciszewska-Pacak M, Nilsson L, Nielsen TH, Johansen E, Gronlund M, Jakobsen I, Albrechtsen M: Investigations of barley stripe mosaic virus as a gene silencing vector in barley roots and in Brachypodium distachyon and oat. Plant Methods 2010, 6:26.

34. Payne PI, Nightingale MA, Krattiger AF, Holt LM: The relationship between HMW glutenin subunit composition and the bread-making quality of British-grown wheat varieties. J Sci Food Agric 1987, 40:51-65.

35. Caruso C, Chilosi G, Leonardi L, Bertini L, Magro P, Buonocore V, Caporale C: A basic peroxidase from wheat kernel with antifungal activity. Phytochemistry 2001, 58:743-750.

36. Shewry PR, Halford NG: Cereal seed storage proteins: structures, properties and role in grain utilization. J Exp Bot 2002, 53:947-958.

37. Yamashita $H$, Nanba $Y$, Onishi M, Kimoto M, Hiemori M, Tsuji H: Identification of a wheat allergen, Tri a $\mathrm{Bd} 36 \mathrm{~K}$, as a peroxidase. Biosci Biotech Bioch 2002, 66:2487-2490.

38. Payne PI, Law CN, Mudd EE: Control by Homoeologous Group 1 Chromosomes of the High-Molecular-Weight Subunits of Glutenin, a Major Protein of Wheat Endosperm. Theor Appl Gene 1980, 58:113-120.

39. Lawrence GJ, Shepherd KW: Inheritance of Glutenin Protein Subunits of Wheat. Theor Appl Genet 1981, 60:333-337.

40. Shewry PR, Napier JA, Tatham AS: Seed Storage Proteins - Structures and Biosynthesis. Plant Cell 1995, 7:945-956.

41. Brites C, Carrillo JM: Influence of high molecular weight (HMW) and low molecular weight (LMW) glutenin subunits controlled by Glu-1 and Glu-3 loci on durum wheat quality. Cereal Chem 2001, 78:59-63.

42. Zhu YF, Li YW, Chen Y, Li H, Liang H, Yue SJ, Zhang AM, Zhang XQ, Wang DW, Jia X: Generation and characterization of a high molecular weight glutenin 1Bx14-deficient mutant in common wheat. Plant Breeding 2005, 124:421-427.

43. Liu X, Jin W, Liu J, Zhao H, Guo A: Transformation of wheat with the HMW-GS 1Bx14 gene without markers. Russ J Genet 2011, 47:182-188.

44. Xu H, Wang RJ, Shen X, Zhao YL, Sun GL, Zhao HX, Guo AG: Functional properties of a new low-molecular-weight glutenin subunit gene from a bread wheat cultivar. Theor App/ Genet 2006, 113:1295-1303.

45. Campbell J, Huang L: Silencing of multiple genes in wheat using barley stripe mosaic virus. J Biotech Res 2010, 2:12-20.

46. Scofield SR, Nelson RS: Resources for virus-induced gene silencing inthe grasses. Plant Physiol 2009, 149:152-157.
47. Bruun-Rasmussen M, Madsen $C T$, Jessing S, Albrechtsen M: Stability of Barley stripe mosaic virus - Induced gene silencing in barley. Mol Plant Microbe In 2007, 20:1323-1331.

48. Barro F, Rooke L, Békés F, Gras P, Tatham AS, Fido R, Lazzeri PA, Shewry PR, Barceló P: Transformation of wheat with high molecular weight subunit genes results in improved functional properties. Nat Biotechnol 1997, 15:1295-1299.

49. Alvarez ML, Gomez M, Carrillo JM, Vallejos RH: Analysis of dough functionality of flours from transgenic wheat. Mol Breeding 2001, 8:103-108.

50. Petty ITD, Hunter BG, Wei N, Jackson AO: Infectious barley stripe mosaic virus RNA transcribed in vitro from full-length genomic cDNA clones. Virology 1989, 171:342-349.

51. Pfaffl MW, Horgan GW, Dempfle L: Relative expression software tool (RESTC) for group-wise comparison and statistical analysis of relative expression results in real-time PCR. Nucleic Acids Res 2002, 30:e36.

doi:10.1186/1471-2229-12-141

Cite this article as: Ma et al:: Virus-induced gene-silencing in wheat spikes and grains and its application in functional analysis of HMW-GSencoding genes. BMC Plant Biology 2012 12:141.

\section{Submit your next manuscript to BioMed Central and take full advantage of:}

- Convenient online submission

- Thorough peer review

- No space constraints or color figure charges

- Immediate publication on acceptance

- Inclusion in PubMed, CAS, Scopus and Google Scholar

- Research which is freely available for redistribution

Submit your manuscript at www.biomedcentral.com/submit
C) Biomed Central 